\title{
Objective measurements of nasal function: necessary before nasal surgery?
}

This extra thick December issue of our Journal gives us a number of interesting data on the objective measurements of nasal function.

When we discuss nasal dysfunction, we think primarily of nasal obstruction. However, other clinical signs like rhinorrheoa, sneezing, itching, burning and loss of smell ${ }^{(1,2)}$, as well as perception of the form and aesthetics of the nose should not be neglected ${ }^{(3,4)}$. During the last decades, we have significantly increased our knowledge on nasal function. We are more aware of the role of questioning the patients about their symptoms, about their most bothersome symptoms and also their quality of life ${ }^{(3-7)}$, and we more often report on objective measurements of nasal obstruction like PNIF, acoustic rhinometry and rhinomanometry. It has clearly been shown that the correlation between symptoms of nasal obstruction and objective measurements is low ${ }^{(8,9)}$. In this issue of the journal, Thorstensen and colleagues show that patients with asthma or reduced FEV1 (\% predicted) have a higher subjective sensation of nasal obstruction compared to controls, despite similar PNIF values in both groups ${ }^{(10)}$.

It has been shown that objective airway function measurements increase the chance of a positive outcome of septal surgery ${ }^{(11,12)}$. However, many colleagues still do not use objective nasal function measurements in their daily practice. In contrast to pulmonologists or allergists routinely performing pulmonary function testing, rhinologists do not always feel the need to objectively quantify the nasal flow prior to surgery. Of note, rhinologists rely on nasal endoscopy for the evaluation of the nasal mucosa and anatomy. A nasal endoscopy (preferably a thin $2.7 \mathrm{~mm}$ ) is a very useful tool to determine the amount of nasal obstruction and may also reveal nasal valve deficiency. The limitations of endoscopic evaluation, however, are the subjectivity of the findings. In lung function measurements different sets of measurements have been described to be relevant: a simple PEF and FEV1 ${ }^{(13)}$, but also more elaborate measurements like diffusing capacity (DLCO), exhaled pulmonary NO (FeNO) and finally forced oscillation technique (FOT) ${ }^{(14,15)}$. The values obtained during lung function tests are interpreted in relation to height, sex and age. In the rhinology field, we have defined how the diagnostic tests have to be performed ${ }^{(16-18)}$ and what are normal values for PNIF ${ }^{(19-21)}$, acoustic rhinometry ${ }^{(22-25)}$ and rhinomanometry ${ }^{(26)}$. Also, at least for PNIF, the minimum clinically important difference of $20 \mathrm{~L} / \mathrm{min}$ has been defined ${ }^{(27)}$. However, not all data are available for different subpopulations based on race, sex and age. It has been argued that it is impossible to measure nasal function reliably because of the nasal cycle and that only measurements after decongestion are reliable ${ }^{(28)}$. However, it is now possible to measure one side at a time, even in PNIF (20), and the combination of different methods probably can further improve the quality of our diagnostics ${ }^{(29)}$. There is some indication that PNIF before and after decongestion can discriminate between structural and mucosal reasons for nasal obstruction: a lack of improvement in PNIF of at least 20L/min or $20 \%$ pointing to a structural cause of obstruction ${ }^{(30)}$. Also, and maybe most importantly, the fact that outcomes of (septal) surgery significantly improve when patients are selected based on nasal function measurements ${ }^{(11,12)}$ and that PNIF has been shown to be a useful tool to measure treatment of effect in children with allergic rhinitis ${ }^{(31)}$ points to the usefulness of objective nasal function measurements.

Nowadays, we do not perform a FESS without having performed nasal endoscopy and CT scan. We have defined what improvement in QOL questionnaires defines a relevant improvement for our patients. Acoustic rhinometry has shown to be accurate in the diagnosis and follow-up of nasal polyps ${ }^{(15)}$. Smell testing remains a diagnostic test mostly being performed upon indication ${ }^{(1)}$, and the amount of secretions in patients with rhinorrhoea or post-nasal drip are rarely quantified. Therefore, there is still a long way to go in the quantification of the symptom severity in patients suffering from chronic (sino)nasal inflammation.

For the future we need to decide which tests are mandatory for the evaluation of nasal dysfunction before and after medical or surgical treatment. Furthermore, the indications for surgery should be fine-tuned on the base of objective and subjective parameters. When do we decide to operate? What is an anatomical obstruction? What is mainly mucosal? Can we objectively measure nasal blockage in patients with CRSWNP and should that influence our decision to operate?

At present, we have not defined which tests we think are needed in various nasal diseases nor which cut-off values are 
relevant to decide on a certain treatment. The latter seems to be challenging given the large interindividual variability in objective data on the one hand and the subjective burden on the other hand. We have not defined the values of any functional test before a septal correction that point to a high change of success, we have not defined what we call valve deficiency, nor do we know relevant values for reversibility. As in lower airways measurements the time has come to define minimal, optimal and relevant measurements of nasal function. We have to understand whether these tests can help us to determine chance of surgical success.

We here call for starting the discussion among rhinologists: do we need objective tests in our daily practice? Which tests should be performed and what consequences are we going to take from these measurements?

Health insurance companies in the USA mandate a trial of medical therapy consisting of intranasal corticosteroids prior to septoplasty regardless of clinical assessment ${ }^{(32)}$. In some countries, attempts are made by insurance companies to use the results of nasal function testing as an objective decision criterion whether a functional septorhinoplasty is indicated or not (33). We plead for pro-activity in defining ourselves what needs to be done before (surgical) interventions. That will also enable us to determine which data are not available at the moment and which studies have to be done to further improve our possibilities to predict optimal outcome of our procedures.

Finally: the journal is flourishing. We receive more and more good papers probably stimulated by our impact factor of 2.8 . We increased the number of pages in this issue of the journal to accommodate more papers. We hope you enjoy the extra reading and on behalf of the whole Rhinology team, we wish you all a very happy 2015.

\section{References}

1. Hellings PW, Scadding G, Alobid I, Bachert C, Fokkens WJ, Gerth van Wijk R, et al. Executive summary of European Task Force document on diagnostic tools in rhinology. Rhinology. 2012; 50: 339-352.

2. Minwegen F, Thomas JP, Bernal-Sprekelsen M, Dazert S, Minovi A. Predictive value of disease severity on self-reported rating and quantitative measures of olfactory function outcomes after primary endoscopic sinus surgery. A prospective study. Rhinology. 2014; 52: 437-443.

3. Bulut C, Wallner F, Plinkert PK, Baumann I. Development and validation of the Functional Rhinoplasty Outcome Inventory 17 (FROI-17). Rhinology. 2014; 52: 315-319.

4. Takhar A, Stephens J, Randhawa PS, Poirrier $A L$, Andrews P. Validation of the sino-nasal outcome test-23 in septorhinoplasty surgery. Rhinology. 2014; 52: 320-326.

5. Bizaki AJ, Taulu R, Numminen J, Rautiainen M. Quality of life after endoscopic sinus surgery or balloon sinuplasty: A randomized clinical study. Rhinology. 2014; 52: 300-305.

6. Taylor RJ, Miller jD, Rose AS, Drake AF, Zdanski CJ, Senior BA, et al. Comprehensive quality of life outcomes for pediatric patients undergoing endoscopic sinus surgery Rhinology. 2014; 52: 327-333.

7. Aboud SK, Husain S, Gendeh BS. Comparison between endonasal endoscopic polyp size scores and quality of life outcome after optimal medical treatment. Rhinology. 2014; 52: 334-340.

8. Salihoglu M, Cekin E, Altundag A, Cesmeci E. Examination versus subjective nasal obstruction in the evaluation of the nasal septal deviation. Rhinology. 2014; 52: 122 126.

9. Sipila J, Suonpaa J, Laippala P. Sensation of nasal obstruction compared to rhinomano- metric results in patients referred for septoplasty. Rhinology. 1994; 32: 141-144.

10. Thorstensen WM, Sue-Chu M, Bugten V, Cvancarova M, Steinsvåg SK. The determining factors of peak nasal inspiratory flow and perception of nasal airflow in asthmatics. Rhinology. 2014; 52: 348-354.

11. Fyrmpas G, Kyrmizakis D, Vital V, Constantinidis J. The value of bilateral simultaneous nasal spirometry in the assessment of patients undergoing septoplasty. Rhinology. 2011; 49: 297-303.

12. Sipila J, Suonpaa J. A prospective study using rhinomanometry and patient clinical satisfaction to determine if objective measurements of nasal airway resistance can improve the quality of septoplasty. Eur Arch Otorhinolaryngol. 1997; 254: 387-390.

13. Miller MR, Hankinson J, Brusasco V, Burgos F, Casaburi R, Coates A, et al. Standardisation of spirometry. Eur Respir J. 2005; 26: 319 338.

14. Culver BH. How should the lower limit of the normal range be defined? Respiratory care. 2012; 57: 136-145.

15. Ruppel GL, Enright PL. Pulmonary function testing. Respiratory Care. 2012; 57: 165-175.

16. Clement PA. Committee report on standardization of rhinomanometry. Rhinology. 1984; 22: 151-155.

17. Clement PA, Gordts F. Consensus report on acoustic rhinometry and rhinomanometry. Rhinology. 2005; 43: 169-179.

18. Chaves C, de Andrade CR, Ibiapina C. Objective measures for functional diagnostic of the upper airways: practical aspects. Rhinology. 2014; 52: 99-103.

19. Ottaviano G, Scadding GK, Coles S, Lund VJ. Peak nasal inspiratory flow; normal range in adult population. Rhinology. 2006; 44: 32-35.

20. Ottaviano G, Scadding GK, Scarpa B, Accordi
D, Staffieri A, Lund VJ. Unilateral peak nasal inspiratory flow, normal values in adult population. Rhinology. 2012; 50: 386-392.

21. van Spronsen E, Ebbens FA, Fokkens WJ. Normal peak nasal inspiratory flow rate values in healthy children aged 6 to 11 years in the Netherlands. Rhinology. 2012; 50: 22-25.

22. Munoz-Cano R, Salvador $R$, Valero $A$, Berenguer J, Alobid I, Bartra J, et al. Accuracy of acoustic rhinometry versus computed tomography in the evaluation of nasal cavity in patients with nasal polyposis. Rhinology. 2010; 48: 224-227.

23. Haavisto LE, Vahlberg TJ, Sipila JI. Reference values for acoustic rhinometry in children at baseline and after decongestion. Rhinology. 2011; 49: 243-247.

24. Millqvist E, Bende M. Reference values for acoustic rhinometry in subjects without nasal symptoms. Am J Rhinol. 1998; 12: 341343.

25. Tantilipikorn P, Jareoncharsri P, Voraprayoon S, Bunnag C, Clement PA. Acoustic rhinometry of Asian noses. Am J Rhinol. 2008; 22: 617-620.

26. Merkle J, Kohlhas L, Zadoyan G, Mösges R, Hellmich M. Rhinomanometric reference intervals for normal total nasal airflow resistance. Rhinology. 2014; 52: 292-299.

27. Timperley D, Srubisky A, Stow N, Marcells GN, Harvey RJ. Minimal clinically important differences in nasal peak inspiratory flow. Rhinology. 2011; 49: 37-40.

28. Moore M, Eccles R. Normal nasal patency: problems in obtaining standard reference values for the surgeon. J Laryngol Otol. 2012; 126: 563-569.

29. Ottaviano G, Lund VJ, Nardello E, Scarpa B, Frasson G, Staffieri A, et al. Comparison between unilateral PNIF and rhinomanometry in healthy and obstructed noses. Rhinology. 2014; 52: 25-30. 
30. Chin D, Marcells G, Malek J, Pratt E, Sacks R, Snidvongs $K$, et al. Nasal peak inspiratory flow (NPIF) as a diagnostic tool for differentiating decongestable from structural nasal obstruction. Rhinology. 2014; 52: 116-121.

31. de Souza Campos Fernandes S, Ribeiro de Andrade C, da Cunha Ibiapina C. Application of Peak Nasal Inspiratory Flow reference values in the treatment of allergic rhinitis. Rhinology. 2014; 52: 133-136.

32. Sedaghat AR, Busaba NY, Cunningham MJ, Kieff DA. Clinical assessment is an accurate predictor of which patients will need septoplasty. Laryngoscope. 2013; 123: 48-52.

33. Clement PA, Halewyck S, Gordts F, Michel O. Critical evaluation of different objective techniques of nasal airway assessment: a clinical review. Eur Arch Otorhinolaryngol. 2014; 271: 2617-2625.
Wytske J. Fokkens, Editor-in Chief Amsterdam, the Netherlands
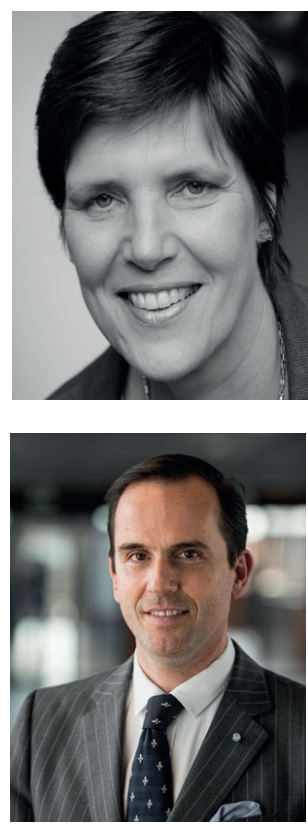
Amsterdam, the Netherlands
Ams 